\title{
SKENARIO KONSEKUENSI ANALISIS PENGANGKUTAN LNG SEMARANG-YOGYAKARTA DENGAN SIMULASI ALOHA
}

\author{
Didik Supriyadi* \\ Program Studi Teknik Kimia, Institut Teknologi Sumatera (ITERA) \\ *Didik.supriyadi@tk.itera.ac.id
}

\begin{abstract}
Liquefied Natural Gas (LNG) is one of the potential alternative fuels to replace conventional fuels. Using LNG as fuel in Indonesia especially Yogyakarta will give many advantages, for instance, reduced greenhouse gas emissions so that eco-city in Yogyakarta can be realized. Although LNG has many advantages, LNG still contains many hazards whether during storage or distribution, the major hazard is radiant heat. This study aims to analyze and simulate hazard scenarios when transporting LNG such as fire pools, fireballs and vapor clouds and establishing exclusion zone by Areal Location of Hazardous Atmospheres (ALOHA) simulation. This study assumes that the diameter of the tank leak is 1 in and 3 in. The simulation results the exclusion zone from pool fire's heat radiation from 1 in and 3 in leaks are more than $14 \mathrm{~m}$ and $39 \mathrm{~m}$. While the safe distance of the fireball is $799 \mathrm{~m}$. While in the distance vapor clouds that have a possibility of fire for the diameter leakage of 1 and 3 in are $21 \mathrm{~m}$ and $59 \mathrm{~m}$.
\end{abstract}

Keyword: consequences, ALOHA, LNG, exclusion zone, pool fire, fire ball, vapor cloud.

\section{Pendahuluan}

LNG merupakan salah satu alternatif bahan bakar yang dapat di aplikasikan di Indonesia sebagai pengganti bahan bakar konvensional. Penerapan LNG di Indonesia dapat dilakukan karena salah satunya didukung oleh cadangan gas alam yang melimpah dengan cadangan mencapai 101,2 Trillion Standard Cubic Feet (TSCF) pada tahun 2016 [1]. Apabila LNG dapat diterapkan di Indonesia khususnya di Kota Yogyakarta maka eco-city dapat segera terwujud. Faktor pendukung untuk menjadikan Kota Yogyakarta sebagai pengguna LNG adalah Yogyakarta terletak dekat dengan pelabuhan Tanjung Emas di Semarang sehingga distribusi LNG dapat terjamin Ketika LNG diterapkan di lapangan, LNG dapat didistribusikan ke konsumen dengan moda transportasi laut dan transportasi darat. Keuntungan yang diperoleh apabila pendistribusian LNG dilakukan dengan angkutan darat adalah ongkos produksi yang lebih murah, namun pengangkutan LNG dengan transportasi darat memiliki risiko yang besar terutama apabila terjadi kebocoran LNG selama pengangkutan. LNG merupakan senyawa yang mudah terbakar sehingga apabila terjadi kebocoran selama pengangkutan maka dapat membahayakan para pengendara lainnya. Hal ini disebabkan transportasi darat merupakan jenis transportasi yang banyak digunakan dibandingkan moda transportasi lainnya seperti laut dan udara, sehingga perlu dilakukan kajian tentang bahaya apa saja yang dapat terjadi dan menetukan jarak aman (exclusion zone) untuk dilakukan evakuasi jika terjadi kebocoran LNG. Tujuan dari penelitian ini adalah untuk menentukan skenario yang akan terjadi apabila terjadi kebocoran dan menentuka jarak aman bagi para pengendara lainnya dengan menggunakan simulasi ALOHA. Diharapkan hasil yang diperoleh dari simulasi ALOHA dapat menggambarkan keadaan sebenarnya apabila skenario-skenario tersebut terjadi.

Beberapa penelitian telah banyak memanfaatkan simulasi ALOHA untuk mengnalisis suatu bahaya yang belum terjadi atau sudah terjadi. Sebagai contoh penelitian yang dilakukan oleh [2], dimana dilakukan analisis terhadap kecelakaan truk yang mengangkut LPG yang menyebakan kebakaran dan ledakan. Penelitian ini menggunakan ALOHA dan PHAST untuk menganalisis kejadian tersebut. Kesimpulan yang diperoleh bahwa kedua simulasi tersebut memberikan hasil yang hampir sama dengan kejadian sebenarnya. Penelitian yang dilakukan oleh [3] mensimulasikan penyebaran gas beracun dengan mengambil contoh gas klorin, epiklorohidrin dan fosfogen dengan menggunakan ALOHA. Penelitian lainnya menggunakan ALOHA untuk menganalisis kebocoran gas alam pada pembangkit listrik, hasil yang diperoleh dari ALOHA digunakan sebagai pedoman dasar perusahaan dalam rencana pemasangan pipa baru dan pembangun pembangkit listrik dengan gas alam [4]. 
LNG merupakan bahan bakar yang ramah lingkungan karena menghasilkan emisi gas $\mathrm{CO}_{2}, \mathrm{NO}_{x}$ yang lebih rendah dan tidak menghasilkan gas $\mathrm{SO}_{x}$ dan particulate matter. Meskipun memiliki banyak keunggulan, LNG masih menyimpan bahaya apabila terjadi kebocoran ke lingkungan. Skenario bahaya yang mungkin terjadi apabila LNG mengalami kebocoran diantaranya asphyxiation, panas radiasi, ledakan, awan uap dan Boiling Liquid Expanding Explosion (BLEVE). Asphyxiation merupakan keadaan dimana kadar oksigen berkurang karena keberadaan LNG yang keluar ke lingkungan. Panas radiasi yang dihasilkan oleh LNG akan lebih besar $57 \%$ dibandingkan dengan panas yang dihasilkan oleh bensin dikarenakan pembakaran LNG sedikit menghasilkan jelaga. Oleh karena itu setiap fasilitas yang terdapat LNG harus ditentukan radius aman (exclusion zone) berdasarkan besaran paparan panas radiasi seperti pada Tabel 1.

Tabel 1. Panas radiasi dan bahayanya

\begin{tabular}{|c|l|}
\hline $\begin{array}{c}\text { Fluk Panas } \\
\text { Btu/jam.ft }\end{array}$ & \\
\hline $\begin{array}{c}1.600 \\
\left(5 \mathrm{~kW} / \mathrm{m}^{2}\right)\end{array}$ & $\begin{array}{l}\text { Apabila terkena manusia akan mengakibatkan sakit dalam 15-30 } \\
\text { detik, tidak membahayakan manusia }\end{array}$ \\
\hline $\begin{array}{c}4.000 \\
\left(12 \mathrm{~kW} / \mathrm{m}^{2}\right)\end{array}$ & $\begin{array}{l}\text { Combustible material dapat terbakar apabila terkena panas dalam } \\
\text { waktu lama. }\end{array}$ \\
\hline $\begin{array}{c}6.700 \\
\left(21 \mathrm{~kW} / \mathrm{m}^{2}\right)\end{array}$ & $\begin{array}{l}\text { Bagunan dapat terbakar apabila terkena panas dalam waktu yang } \\
\text { lama. }\end{array}$ \\
\hline 10.000 & Baja pada bangunan akan kehilangan kekuatanya. \\
\hline$\left(32 \mathrm{~kW} / \mathrm{m}^{2}\right)$ & \\
\hline
\end{tabular}

Ledakan merupakan kejadian dimana keluarnya energi pada suatu sistem dalam bentuk tekanan dan suhu yang tinggi akibat perubahan kimia, kegagalan peralatan dan adanya confinement atau partial confinement [5]. Awan uap yang dihasilkan oleh LNG meskipun tidak beracun namun dapat menghasilkan api apabila terdapat sumber api, hal ini dikarenakan konsentrasi LNG yang terbentuk dapat berada diantara Lower Flammability Limit (LFL) dan Upper Flammability Limit (UFL). BLEVE merupakan kejadian yang disebabkan oleh kegalalan tangki dalam menahan tekanan yang di dalam tangki, biasanya kenaikan tekanan disebabkan karena adanya pemanasan.

\section{Metode}

Simulasi ALOHA merupakan software simulasi yang dikembangkan oleh beberapa organisasi diataranya United States Environmental Protection Agency (USEPA), Chemical Emergency Preparedness and Prevention Office (CEPPO) dan National Oceanic and Atmospheric Administration Office of Response and Restoration (NOAA). ALOHA merupakan software yang dapat digunakan secara gratis dan legal dan telah mengalami banyak perkembangan dengan versi terbaru ALOHA 5.4.7. Pada penelitian ini dibuat dua skenario untuk simulasi menggunakan ALOHA dengan volume LNG di dalam tangki 47,7 $\mathrm{m}^{3}$.

Table 2. Metode Percobaan

\begin{tabular}{|l|l|l|}
\hline Parameter & Skenario 1 & Skenario 2 \\
\hline Diameter lubang & 1 in & 3 in \\
\hline Suhu lingkungan & $26,3^{\circ} \mathrm{C}$ & $26,3^{\circ} \mathrm{C}$ \\
\hline Kecepatan angina & $3,3 \mathrm{~m} / \mathrm{s}$ & $3,3 \mathrm{~m} / \mathrm{s}$ \\
\hline Kelembaban udara & $79 \%$ & $79 \%$ \\
\hline Diameter tangki & $2,338 \mathrm{~m}$ & $2,338 \mathrm{~m}$ \\
\hline Panjang tangki & $12,3 \mathrm{~m}$ & $12,3 \mathrm{~m}$ \\
\hline Tekanan design tangki & $670.000 \mathrm{~Pa}$ & $670.000 \mathrm{~Pa}$ \\
\hline Tipe stabilitas atmosfer & $\mathrm{D}$ & $\mathrm{D}$ \\
\hline
\end{tabular}

\section{Hasil dan Pembahasan}

ALOHA digunakan untuk melakukan simulasi tiga skenario konsekuensi yang mungkin terjadi berdasarkan probabilitas kejadian yang dihasilkan dari penelitian sebelumnya [6] yaitu kolam api (pool fire), bola api (fire ball) dan awan uap (vapor cloud). Ledakan tidak masuk ke dalam skenario karena diasumsikan di jalan raya tidak terdapat confinement. Ketiga skenario yang dibuat ini terjadi apabila terjadi kebocoran LNG selama proses pengangkutan 


\subsection{Kolam api}

Skenario pertama yang disimulasikan adalah kolam api (pool fire). Kolam api yang terbentuk akan menghasilkan panas radiasi yang dapat membahayakan para pengendara yang berada disekitar truk pengangkut LNG. Panas radiasi yang dihasilkan dari diameter lubang 1 in dan 3 in dapat dilihat pada Gambar 1. Pada Gambar 1(a) bahwa panas radiasi yang dihasilkan dari kebocoran tangki 1 in yang dapat membahayakan para pengandara lain berada pada radius kurang dari $10 \mathrm{~m}$ dengan besar panas radiasi lebih dari $10 \mathrm{~kW} / \mathrm{m}^{2}$, sedangkan untuk panas radiasi sebesar $5 \mathrm{~kW} / \mathrm{m}^{2}$ yang menyebabkan luka bakar tingkat 2 berada pada radius $10 \mathrm{~m}$ sedangkan jarak yang hanya menyebabkan luka dengan panas radiasi lebih dari $2 \mathrm{~kW} / \mathrm{m}^{2}$ yaitu 14 meter. Jarak aman atau exclusion zone untuk dilakukan evakuasi bagi pengendara lain apabila terjadi kebocoran pada skenario 1(a) adalah lebih dari $14 \mathrm{~m}$.

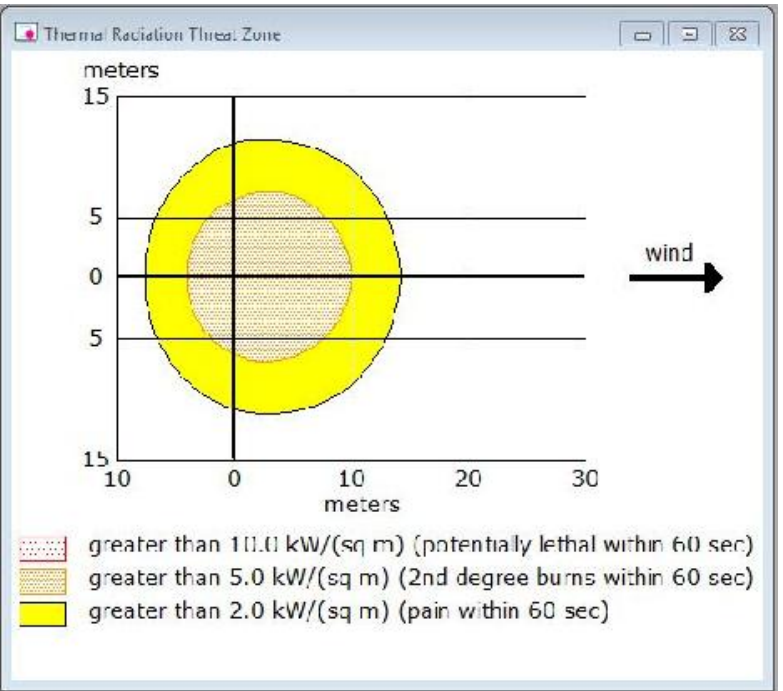

(a)

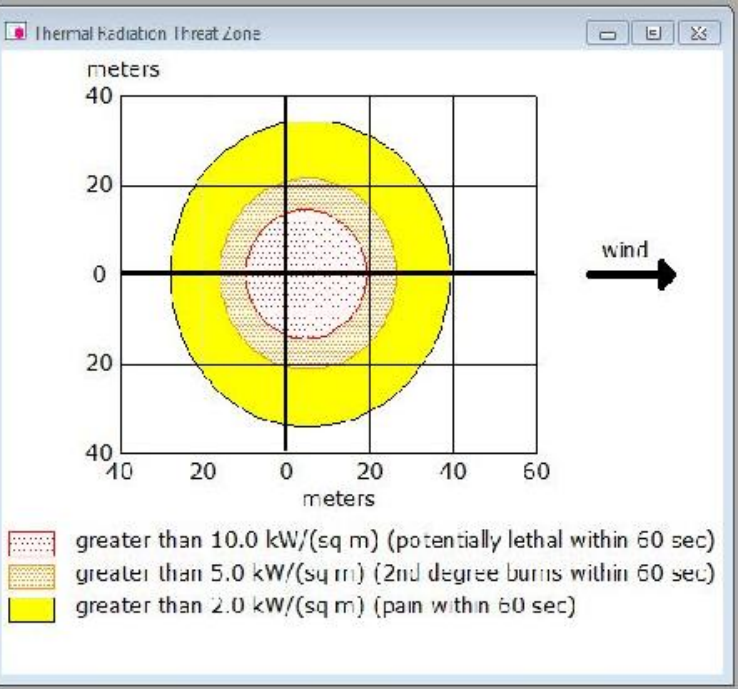

(b)

Gambar 1. Kolam api (a) 1 in dan (b) 3 in

Gambar 1(b) merupakan profil panas radiasi yang dihasilkan dari kebocoran lubang dengan diameter 3 in, dimana panas radiasi lebih dari $19 \mathrm{~kW} / \mathrm{m}^{2}$ berada pada radius $19 \mathrm{~m}$, sedangkan untuk panas radiasi lebih besar dari $5 \mathrm{~kW} / \mathrm{m}^{2}$ berada pada radius $27 \mathrm{~m}$ sedangkan untuk panas radiasi lebih besar dari 2 $\mathrm{kW} / \mathrm{m}^{2}$ berada pada radius $39 \mathrm{~m}$. Radius aman agar para pengguna jalan tidak terkena panas radiasi yang dihasilkan adalah lebih dari $39 \mathrm{~m}$. Perbedaan radius aman yang dihasilkan dari kasus diatas disebabkan waktu pengosongan diameter lubang 3 in lebih cepat dibandingkan dengan diameter 1 in sehingga diameter yang dihasilkan lebih besar.

\subsection{Bola Api}

Bola api merupakan skenario kedua yang disimulasikan dengan ALOHA, pada skenario ini diasumsikan seluruh LNG yang berada di dalam tangki terbakar yaitu sebesar $20.748 \mathrm{~kg}$ dengan tekanan di dalam tangki sebesar 889.424 Pa. Tekanan ini di atas tekanan design tangki sebesar 670.000 Pa. Dari hasil simulasi diperoleh bahwa diameter bola api sebesar $159 \mathrm{~m}$ dengan durasi 11 detik. Hasil yang diperoleh ini tidak terlalu berbeda dengan perhitungan yang dilakukan oleh [6] dimana diameter bola api yang terbentuk adalah 162,48 $\mathrm{m}$ dengan durasi 11,21 detik. Beberapa penelitian yang telah dilakukan tentang bola api diantaranya penelitian untuk menganalisis bola api yang terbentuk akibat accident yang menimpa truk pengangkut LNG di Spanyol pada tahun 2011, dimana LNG sebanyak $21.589 \mathrm{~kg}$ menghasilkan bola api dengan diameter 157,3 m dengan durasi 12,2 detik [7]. Penelitian yang dilakukan oleh [8] untuk LNG sebesar $19.000 \mathrm{~kg}$ menghasilkan bola api dengan diameter 159,28 m dengan durasi 10,69 detik. Panas radiasi yang dihasilkan oleh bola api dapat dilihat pada Gambar 2. 


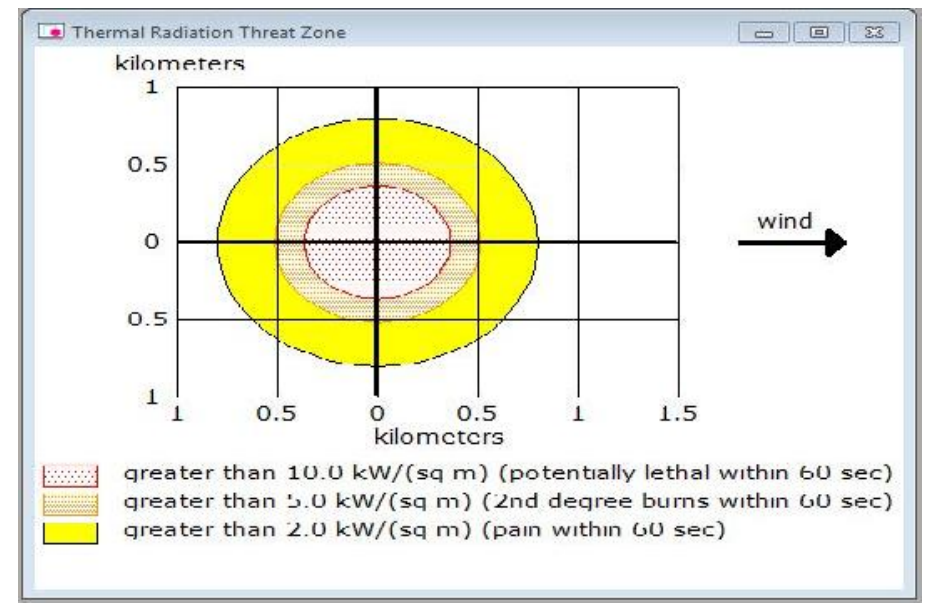

Gambar 2. Bola api

Radius bahaya yang dapat menyebabkan kematian dari bola api untuk kasus ini adalah $364 \mathrm{~m}$, dimana pada radius ini panas radiasinya lebih dari $10 \mathrm{~kW} / \mathrm{m}^{2}$, sedangkan radius untuk panas radiasi lebih dari 5 $\mathrm{kW} / \mathrm{m}^{2}$ adalah $514 \mathrm{~m}$. Radius aman bagi manusia dengan panas radiasi lebih dari $2 \mathrm{~kW} / \mathrm{m}^{2}$ berada pada jarak $799 \mathrm{~m}$.

\subsection{Awan uap}

Awan uap terbentuk apabila disekitar tumpahan tidak terdapat sumber api, sehingga LNG yang memiliki titik didih dibawah suhu udara ambient akan menguap secara cepat. Meskipun hanya terbentuk awan uap, awan uap tersebut dapat mengakibatkan flash fire apabila terdapat sumber api, hal ini disebabkan karena konsentrasi awan uap yang terbentuk dapat memiliki konsentrasi diantaran LFL dan UFL. Hal ini dapat dilihat pada Gambar 3(a) untuk diameter lubang 1 in konsentrasi uap LNG yang dapat membahayakan dengan konsentrasi LNG sebesar 60\% Lower Explosive Limit (LEL) berada pada jarak $21 \mathrm{~m}$ sedangkan untuk konsentrasi LNG sebesar 10\% LEL berada pada radius $75 \mathrm{~m}$. Pada Gambar $3(\mathrm{~b})$ dengan diameter kebocoran 3 in, zona bahaya dimana konsentrasi LNG mencapai 60\% LEL berada pada radius $59 \mathrm{~m}$ dan untuk konsentrasi $10 \% \mathrm{LEL}$ berada pada radius $164 \mathrm{~m}$. Lebih kecilnya radius yang dihasilkan dari diameter lubang 1 in dibandingkan dengan diameter lubang 3 in pada konsentrasi LNG yang sama dikarenakan LNG yang keluar dari lubang 1 in membutuhkan waktu yang lebih lama dibandingkan melalui lubang dengan diameter 3 in sehingga LNG yang keluar dari lubang 1 in lebih banyak terdispersi ke lingkungan lebih dahulu dibandingkan dengan LNG yang keluar dari lubang 3 in.

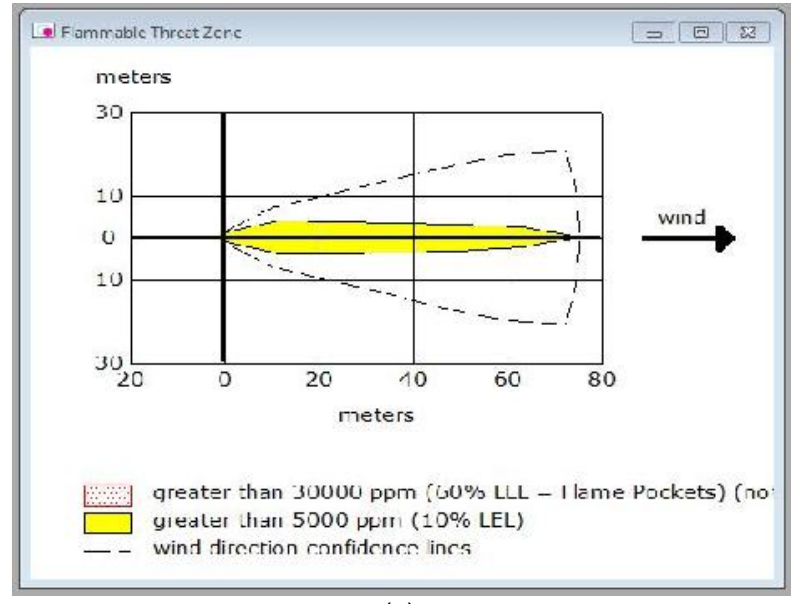

(a)

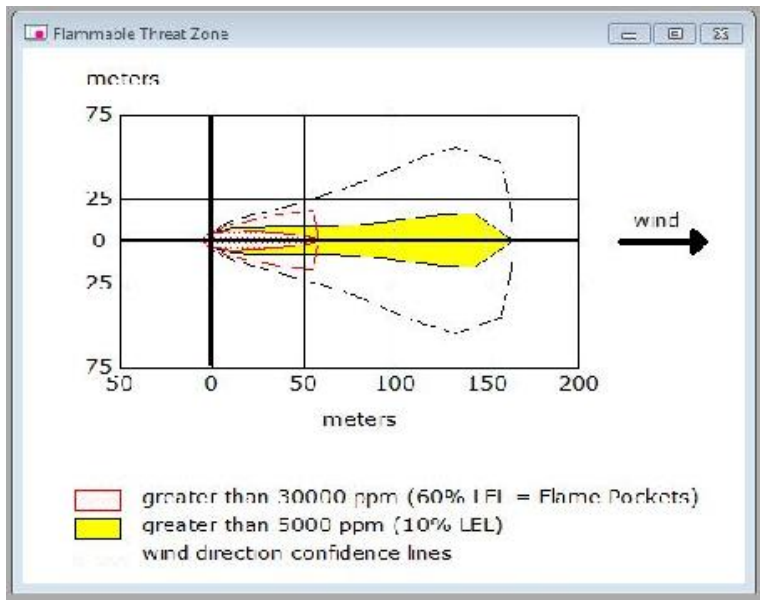

(b)

Gambar 3. Awan uap (a) 1 in dan (b) 2 in 


\section{Rekomendasi}

Rekomendasi yang dapat diberikan kepada pemerintah atau organnisasi yang akan menggunakan LNG sebagai salah satu alternative bahan bakar terkait dengan bahaya yang dimiliki diantaranya :

1. Radius aman apabila terjadi kolam api dengan diameter kebocoran tangki pengangkut 1 in dan 3 in adalah lebih dari $14 \mathrm{~m}$ dan $39 \mathrm{~m}$.

2. Radius aman apabila terjadi bola api pada tangki truk penyimpan LNG lebih dari $799 \mathrm{~m}$.

3. Radius bahaya awan uap yang terbentuk dari diameter lubang 1 in dan diameter lubang 3 in adalah $21 \mathrm{~m}$ dan $59 \mathrm{~m}$.

\section{Daftar Pustaka}

[1] BP, "BP Statistical Review of World Energy 2017," Br. Pet., no. 66, pp. 1-52, 2017.

[2] N. Bariha, I. M. Mishra, and V. C. Srivastava, "Fire and explosion hazard analysis during surface transport of liquefied petroleum gas (LPG): A case study of LPG truck tanker accident in Kannur, Kerala, India," J. Loss Prev. Process Ind., vol. 40, pp. 449-460, 2016.

[3] J. M. Tseng, T. S. Su, and C. Y. Kuo, "Consequence evaluation of toxic chemical releases by ALOHA," Procedia Eng., vol. 45, pp. 384-389, 2012.

[4] H. Shao and G. Duan, "Risk quantitative calculation and ALOHA simulation on the leakage accident of natural gas power plant," Procedia Eng., vol. 45, no. 4, pp. 352-359, 2012.

[5] I. of C. Engineers, "BP Process Safety Series LNG Fire Protection and Emergency Response," in BP Process Safety Series, IChemE, 2007.

[6] Supriyadi, Didik; Moh. Fahrurrozi; Perdana, Indra, "Pemanfaatan LNG Sebagai Bahan Bakar Kendaraan Umum di Yogyakarta: Tinjauan Aspek Keselamatan Dalam Pengangkutan dan Penyimpanan," 2016, vol. 2, no. 2008, pp. 198-205.

[7] J. M. B. Martinez, "Liquefied natural gas road tanker explosion," 17th Int. Conf. Exhib. Liquified Nat. Gas 2013, LNG 2013, vol. 1, pp. 26-38, 2013.

[8] Q. X. Zhang and D. Liang, "Thermal Radiation and impact assessment of the LNG BLEVE fireball," Procedia Eng., vol. 52, pp. 602-606, 2013. 